\title{
Altered hippocampal functional connectivity patterns in patients with cognitive impairments following ischaemic stroke: A resting-state fMRI study
}

\author{
JeYoung Jung a , Rosanna Laverick ${ }^{\mathrm{b}}$, Kurdow Nader ${ }^{\mathrm{c}}$, Thomas Brown ${ }^{\mathrm{e}}$, Haley Morris ${ }^{\mathrm{e}}$, \\ Martin Wilson ${ }^{\mathrm{b}}$, Dorothee P. Auer ${ }^{\mathrm{d}, \mathrm{e}}$, Pia Rotshtein ${ }^{\mathrm{b}, *}$, Akram A. Hosseini ${ }^{\mathrm{b}, \mathrm{e}, \mathrm{f}, *}$

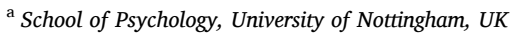 \\ ${ }^{\mathrm{b}}$ School of Psychology, University of Birmingham, UK \\ ${ }^{\mathrm{c}}$ University Hospital Birmingham NHS Trust, Birmingham, UK \\ ${ }^{\mathrm{d}}$ NIHR Nottingham BRC, University of Nottingham, UK \\ e Division of Clinical Neuroscience, University of Nottingham, UK \\ ${ }^{\mathrm{f}}$ Department of Neurology, Nottingham University Hospitals NHS Trust, Queen's Medical Centre, Nottingham, UK
}

\section{A R T I C L E I N F O}

\section{Keywords:}

Ischemic stroke

Cognitive impairment

Hippocampus

Resting-state functional magnetic resonance imaging

Functional connectivity

\begin{abstract}
A B S T R A C T
Background: Ischemic stroke with cognitive impairment is a considerable risk factor for developing dementia. Identifying imaging markers of cognitive impairment following ischemic stroke will help to develop prevention strategies against post-stroke dementia.

Methods: We investigated the hippocampal functional connectivity (FC) pattern following ischemic stroke, using resting-state fMRI (rs-fMRI). Thirty-three cognitively impaired patients after ischemic stroke and sixteen agematched controls with no known history of neurological disorder were recruited for the study. No patient had a direct ischaemic insult to hippocampus on the examination of brain imaging. Seven subfields of hippocampus were used as seeds region for FC analyses.

Results: Across all hippocampal subfields, FC with the inferior parietal lobule was reduced in stroke patients as compared with healthy controls. This decreased FC included both supramarginal gyrus and angular gyrus. The FC of hippocampal subfields with cerebellum was increased. Importantly, the degree of the altered FC between hippocampal subfields and inferior parietal lobule was associated with their impaired memory function. Conclusion: Our results demonstrated that decreased hippocampal-inferior parietal lobule connectivity was associated with cognitive impairment in patients with ischemic stroke. These findings provide novel insights into the role of hippocampus in cognitive impairment following ischemic stroke.
\end{abstract}

\section{Introduction}

Stroke is a worldwide leading cause of death and disability and ischemic stroke accounts for around $71 \%$ of all strokes (Gorelick et al., 2011). Despite intensive treatment, and rehabilitation, more than half of the patients with ischemic stroke cannot return to work due to the remaining physical or cognitive dysfunction (Campbell et al., 2019). Cognitive impairment after a stroke is common and leads to post-stroke dementia (Al-Qazzaz et al., 2014). In particular, stroke patients with cognitive impairment have an increased risk of developing vascular or other types of dementia at 5 years (Wentzel et al., 2001). Patients with ischemic stroke are at increased risk of developing vascular cognitive impairment ranging from mild cognitive impairment (MCI) to vascular dementia (Rockwood et al., 1999). Despite this significant link between ischemic stroke with vascular cognitive impairment (Rockwood et al., 2000), its underlying neural mechanism remains unclear. It is important to identify markers for developing cognitive impairment following ischemic stroke, which might be beneficial to prevent from progression to vascular dementia.

Vascular dementia is characterised by cognitive impairment due to vascular lesions, post-stroke territorial or lacunar infractions, and/or cerebral microbleeds. Although the highest impact of stroke at the time of diagnosis is on the attention and executive functions, memory impairment is prevalent ranging from $23 \%$ to $55 \%$ at 3 months and it

\footnotetext{
* Corresponding authors at: Department of Neurology, Nottingham University Hospitals NHS Trust, Queen's Medical Centre, Nottingham, UK.

E-mail addresses: p.rotshtein@bham.ac.uk (P. Rotshtein), ahosseini@doctors.org.uk (A.A. Hosseini).
} 
remains up to $31 \%$ one year after the stroke onset (Snaphaan and de Leeuw, 2007). The human memory system is a complex structure, with different functionalities (long-term and short-term memory), supported by various brain areas including medial temporal lobe (e.g., hippocampus), inferior and lateral temporal lobe, basal ganglia, cerebellum, and prefrontal cortex (Thompson and Kim, 1996). Based on stroke location and severity, memory functions can be involved and results in memory decline (Al-Qazzaz et al., 2014). As hippocampus play a crucial role in encoding and consolidation of both short-term and long-term memory as well as spatial processing (Bird and Burgess, 2008), here, we focus on hippocampus in patients with cognitive impairment following ischemic strokes.

Changes to the structure and function of the hippocampus (e.g., atrophy or decreased activation) is considered predictive of progression from MCI to Alzheimer's disease (AD) (Barnes et al., 2009). These hippocampal alterations have been associated with cognitive decline or post-stroke dementia (Blum et al., 2012; Gemmell et al., 2012; Yang et al., 2014). Werden et al (2017) reports hippocampal volume loss 6 weeks after ischemic strokes as compared to healthy controls. Hippocampus is composed of cytoarchitectonically different subfields such as cornu ammonis (CA1-CA3), subiculum, and dentate gyrus (DG) (Amunts et al., 2005) and each subfield plays a specific role within the hippocampal circuitry (Berron et al., 2016; Hodgetts et al., 2017; Neunuebel and Knierim, 2014). Especially, in the early stage of AD, neuron loss are more prominent in the CA1 and subiculum (Rossler et al., 2002). The CA3 and DG is associated with auditory immediate recall, while CA1 is related to auditory delayed recall in temporal lobe epilepsy patients with hippocampal sclerosis (Mueller et al., 2012). However, the subfields of hippocampal functional changes after an ischemic stroke and their association with cognitive impairment remain less clear.

Resting-state functional magnetic resonance imaging (rsfMRI) measures the temporal correlation of spontaneous low-fluctuations (typically $<0.1 \mathrm{~Hz}$ ) in the blood oxygenation level-dependent (BOLD) signals among different brain areas, providing a measure of temporal coherence between brain regions at rest - functional connectivity (FC). Studies of rsfMRI have provided important insights in healthy brain systems and in various disorders (Lee et al., 2013; Zhang and Raichle, 2010). FC changes (increased or decreased relative to normal) in prefrontal, temporal, and premotor regions as well as in default mode network (DMN) have been reported in schizophrenia (Garrity et al., 2007; Zhou et al., 2007) and disruptions within the DMN have been observed in Alzheimer's disease (Zhang et al., 2010), major depression (Greicius et al., 2007), and schizophrenia. Further, rsfMRI has been used to aid the diagnosis and assessment of Alzheimer disease (Chen et al., 2011; Zhou et al., 2010) and consciousness level (Vanhaudenhuyse et al., 2010).

Recent rsfMRI studies of stroke patients have demonstrated disruptions in the FC in the lesioned and peri-lesioned parenchyma, followed by connectivity-based reorganization, and subsequent functional recovery (Baldassarre et al., 2016; Kroll et al., 2017; Ovadia-Caro et al., 2014). The interhemispheric FC is reduced after acute ischemia, which correlates with patients' impaired cognitive performance (Carter et al., 2010; Puig et al., 2018). Specifically, the motor network FC is decreased in patients with ischemic stroke (Golestani et al., 2013) and the FC improves alongside with motor function recovery (Wang et al., 2010; Zheng et al., 2016). The FC analyses of DMN after ischemic stroke in patients with cognitive impairment has shown a decreased FC of the precuneus with multiple brain regions such as frontal, temporal and subcortical areas; as well as an increased FC with the middle/inferior temporal gyrus (Sun et al., 2011). Another study has examined the hippocampal FC and its changes related to cognitive therapy (computerassisted cognitive rehabilitation) within 6 months after ischemic stroke (Yang et al., 2014). The patients in their study had abnormal hippocampal FC with insula, cerebellum, prefrontal and temporal cortex, compared with controls. After cognitive therapy, the hippocampal FC with prefrontal cortex and precuneus increased in the patient group, and was associated with improved memory function. A study of patients with transient ischemic attack revealed decreased amplitude of low frequency fluctuation - spontaneous brain activity - in middle temporal gyrus, compared to controls (Lv et al., 2019). These studies have shown that even in those with transient ischemic attacks, the event induces FC alterations in various brain regions. However, there is little known about the impact of FC following an ischemic stroke.

RsfMRI can be useful for clinical investigation when it is included in an existing acute stroke imaging protocol. Necessary rsfMRI scans can be acquired in a relatively short period of time (usually $<10 \mathrm{mins}$ ) with minimal demands on the patient, which makes it as an optimal option for clinical settings. After the acute phase, plasticity-related recovery occurs and improvement can be determined by functional reorganization of brain networks via FC changes (Grefkes and Fink, 2011). Accumulating evidence demonstrates the usefulness of connectivity based approach using rsfMRI to study stroke and its recovery (Grefkes and Fink, 2014; Ovadia-Caro et al., 2014). Accordingly, novel therapeutic approaches employing non-invasive brain stimulation after stroke target modulation of connectivity in neural networks (Grefkes and Fink, 2011; Sehm et al., 2012).

In the current study, we employed rs-fMRI to explore the pattern of hippocampal FC after an ischemic stroke in patients with post-stroke cognitive impairment. To provide detailed hippocampal FC, we used the cytoarchitectonic probabilistic maps of hippocampus, which divides it into 7 subfields (CA1, CA2, CA3, DG, EC, HATA, and Subiculum) (Amunts et al., 2005; Eickhoff et al., 2005). We hypothesized that there could be altered patterns of hippocampal FC in patients after ischemic stroke as compared with controls. The degree of changes in the hippocampal FC would be associated with their impaired memory function.

\section{Materials and methods}

\subsection{Participants}

We used data from the Hippocampal Pathology in Post-Stroke Cognitive Impairment study (HiPPS-CI) (a total of 71 stroke patients and 20 age-matched controls) acquired from two West-Midlands hospitals (Queen Elizabeth Birmingham and Sandwell General Hospital) between July 2015 and January 2019.

Thirty-three patients ( 6 females, mean age $62.5 \pm 13.4$ years) were included in this study. Our inclusion criteria for the study were (a) recent (less than three months) clinically diagnosed ischemic stroke, (b) age $>18$ to $<90$ years, (c) able and willing to provide informed consent and (d) cognitive impairment (Montreal cognitive assessment MoCA $\leq$ $26 / 30$. Stroke patients were excluded from the study if they (a) had contraindication to have MRI e.g. metal foreign body (pacemaker, aneurysm clip, possibility of metal fragments in the eye, etc), (b) unfit or unable to tolerate MRI, (c) severe disabling stroke (m-Rankin Scale > 4) (Fish, 2011), (d) known pre-stroke dementia or cognitive impairment as confirmed by family members or medical documents, (e) if their lesion directly affected the hippocampus region. Stroke patients were recruited within their hospital admission. At this stage, informed consent was taken, and clinical information was recorded. The participants were invited to take part in a cognitive assessment, and have MRI at $3 \mathrm{~T}$ within three months of stroke.

Sixteen age-matched controls with no previous history of neurological disorder ( 8 females, mean age $=61.2 \pm 9.5$ years) were consented during the same period. They were recruited as healthy relatives of stroke patients or from the local community.

The study obtained approval from the UK Health Research Authority and the Research Ethics Committee (15/WM/0209).

\subsection{Clinical and cognitive evaluation}

Clinical profiles were obtained from the clinical records of the patients. The control group provided self-report information of their health. For each participant, we assessed the National Institute of Health 
Stroke Scale (NIHSS) on the day of admission and computed a vascular risk score based on the Framingham stroke risk profile (FSRP). FSRP is an estimate of the individual's stroke risk in the next 10 years, which represents a level of vascular health (Wolf et al., 1991). FSRP includes the following risk factors: age, systolic blood pressure (taken at admission to hospital), antihypertensive medication, diabetes, cigarette smoking, history of cardiovascular disease, and atrial fibrillation. A higher vascular risk score indicated worse prognosis for further stroke incidence, and lower overall vascular health. Cognition was assessed using Montreal Cognitive Assessment, MoCA (Nasreddine et al., 2005) and Birmingham Cognitive Screen, BCoS (Bickerton et al., 2015; Humphreys et al., 2012; Pan et al., 2015). The BCoS assessed the participants' cognitive profiles across cognitive domains including (a) attention and executive function, (b) language, (c) memory, (d) number, and (e) praxis from 22 tasks. Some participants could not complete the sub-questions of each task. A test of verbal fluency (Lezak, 1976) was also included in the cognitive battery, as it is widely used in assessment of neurological patients (Henry and Crawford, 2004; Herbert et al., 2014).

In addition, each participant's functional independence was assessed by using the Barthel index (Mahoney and Barthel, 1965). The hospital anxiety and depression scale (HADS) (Zigmond and Snaith, 1983) was utilised to assess the participants' mood. The MoCA, Barthel and HADS assessments were performed during their hospital admission as part of clinical care or by the Clinical Research Nurses.

\subsection{Statistical analysis}

Differences in demographics and clinical scales between the stroke patients and controls were analysed using a $t$-test for continuous variables (age, years of education, FSRP, MoCA, Barthel, HADS, and verbal fluency) and $\chi^{2}$ test for gender.

The BCoS scores were analysed employing analysis of covariance (ANCOVA) with covariates including the age, gender, and years of education.

All statistical analyses were performed using IBM SPSS Statistics for Windows, version 24.0 (IBM Corporation, Armonk, NY, USA).

\subsection{Image acquisition}

A 3 T Philips Achieva scanner at the Birmingham University Imaging centre was used to acquire imaging data. During the rsfMRI, participants were asked to keep their eyes closed, lie as still as possible and to stay awake (6mins, the total volume: 180 ). Anatomical images were acquired the MPRAGE sequence $(\mathrm{TR}=8.4 \mathrm{~ms}, \mathrm{TE}=3.8 \mathrm{~ms}$, matrix $=288 \times 288$, resolution $=1 \times 1 \times 1 \mathrm{~mm}^{3}$ ) covering the whole head. rsfMRI were obtained using a single-shot echo planer imaging (EPI) sequence (TR = $2000 \mathrm{~ms}$, TE $=35 \mathrm{~ms}$, matrix $=80 \times 80$, number of slices $=32$, resolution $=3 \times 3 \times 3 \mathrm{~mm}^{3}$ ). The scanning protocol included additional image sequences (e.g. T2, FLAIR, MRS, DTI) which will be reported elsewhere. The rsfMRI was the 7th sequence and was collected at about $30 \mathrm{~min}$ into the scanning.

\subsection{Lesion analysis}

Patients' structural images were first wrapped into the MNI space, using the adjusted unified segmentation algorithm (Seghier et al., 2008). Identification and quantification of the ischemic lesions was performed manually by two raters (TB, HM) using MRIcroGL (https://www.nitrc. org/projects/mricrogl). The final lesion constituted the overlapping area across the two raters. The accuracy of the lesion demarcation was confirmed and verified by a Neuroradiologist $(\mathrm{KN})$. Lesion volume reported number of voxels $\left(1 \times 1 \times 1 \mathrm{~mm}^{3}\right)$. The results are summarised in Table 1 . Two patients had a very small lesion, $<1$ voxel size, which was assessed as 0 in the lesion volume. The overlap maps were created in SPM and presented using MRIcroGL (Fig. 1). The location of lesions were widely spread in this sample, with limited lesion overlaps
Table 1

Lesion location and size.

\begin{tabular}{llll}
\hline ID & Lesion Side & Lesion Location & $\begin{array}{l}\text { Lesion Volume } \\
\text { (voxel) }\end{array}$ \\
\hline IS001 & Left & Frontal lobe & 558 \\
IS002 & Left & Basal ganglia & 1 \\
IS004 & Left & Frontal + occipital lobe & 6210 \\
IS005 & Left & Basal ganglia & 37 \\
IS006 & Right & Frontal + parietal lobe & 49 \\
IS007 & Right & Basal ganglia & 276 \\
IS008 & Bilateral & Frontal lobe & 296 \\
IS010 & Bilateral & Basal ganglia & 18 \\
IS011 & Right & Temporal + parietal lobe & 4 \\
IS012 & Right & Basal ganglia & 5 \\
IS013 & Right & Basal ganglia & 35 \\
IS014 & Left & Pons & 40 \\
IS016 & Left & Cerebellum & 42 \\
IS017 & Right & Temporal + parietal lobe & 724 \\
IS018 & Left & Pons & 68 \\
IS019 & Left & Frontal + temporal + parietal lobe & 4808 \\
IS020 & Right & Pons & 15 \\
IS021 & Left & Thalamus & 3 \\
IS022 & Left & Basal ganglia (putamen) & 8 \\
IS023 & Right & Basal ganglia & 323 \\
IS024 & Left & Midbrain & 5 \\
IS026 & Right & Thalamus & 430 \\
IS027 & Bilateral & Cerebellum & 35 \\
IS028 & Bilateral & Frontal lobe & 71 \\
IS029 & Right & Temporal lobe & 75 \\
IS030 & Left & Temporal lobe & 219 \\
IS031 & Bilateral & Frontal lobe & 191 \\
\hline & & & \\
\hline
\end{tabular}

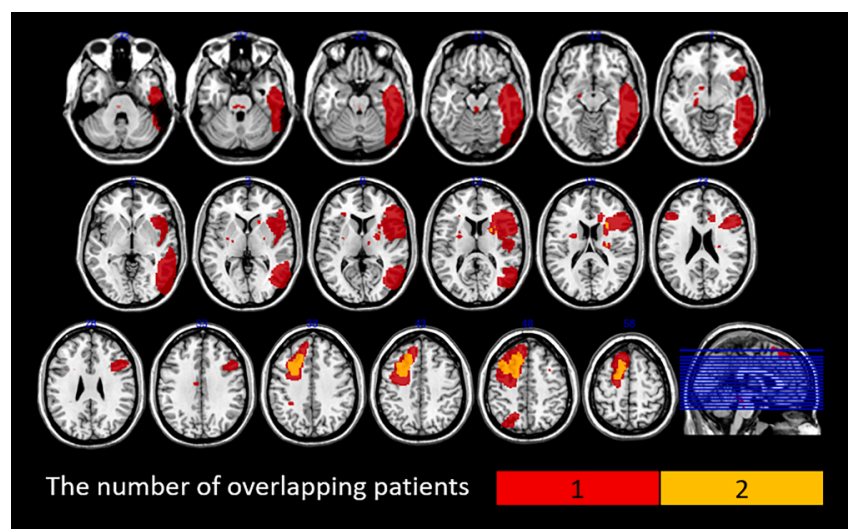

Fig. 1. The overlapping lesion maps.

across patients. No patient had a direct ischaemic insult to hippocampus.

\subsection{Image pre-processing}

Image pre-processing was performed using statistical parametric mapping (SPM 12) software (Wellcome Trust Centre for Neuroimaging) and the Data Processing Assistant for Resting State fMRI (DPARSF Advanced Edition, version 2.3) toolbox (Yan et al., 2016).

SPM 12 was used for slice timing correction, realignment, and coregistration to the individual's structural image. Participants with $>2$ $\mathrm{mm}$ translation or 1 degree of rotation were excluded from the analysis. To reduce the effect of head movements, we used four methods: censoring, global signal regression, 24-motion parameter regression, and scrubbing of high motion time points. Within the DPARSF, nuisance covariates were regressed out and the images were normalized using DARTEL (Ashburner, 2007) and smoothed with and $5 \mathrm{~mm}$ full-width half maximum Gaussian kernel. The results were filtered at 0.01-0.08 $\mathrm{Hz}$ (Satterthwaite et al., 2013). Nuisance covariates included 24 motion 
parameters calculated from the six original motion parameters using Volterra expansion (Friston et al., 1996). Time points with a z-score $>2.5$ from the mean global power or $>1 \mathrm{~mm}$ translation were identified as outliers using the ARtifact detection Tools software package (ART; www.nitrc.org/projects/artifact_detect). Each of these was entered as a covariate. White matter, cerebrospinal fluid, global tissue signal, and lesion volume were covaried out and linear detrending was performed to reduce motion-related artefacts (Anderson et al., 2011; Power et al., 2014; Weissenbacher et al., 2009). Four participants (3 patients and 1 control) were excluded due to having motion $>2 \mathrm{~mm}$ of translation, $1^{\circ}$ of rotation, or $<6 \mathrm{~min}$ of data remaining after scrubbing high motion time points.

\subsection{Functional connectivity analysis}

Seed-based functional connectivity analyses were performed using the DPARSF. For the sub-fields of hippocampus, we used the template from the Anatomy toolbox's cytoarchitectonic probabilistic maps (Fig. 2) (Amunts et al., 2005; Eickhoff et al., 2005). The sub-fields of bilateral hippocampus were included in this analysis as a seed region (CA1, CA2, CA3, DG, EC, HATA, and Subiculum). To generate functional connectivity (FC) maps, bivariate correlations were calculated between each seed and the whole brain voxels. The correlation coefficient map was converted into $\mathrm{z}$ map by Fisher's r-to-z transform to improve the normality (Rosner, 2006). The resultant FC maps were generated for the stroke patients and the control groups using one-sample $t$-test and compared between the groups using t-tests in the SPM 12, accounting for lesion volume, age, gender, and the years of education. The statistical threshold was set at $\mathrm{p}$ FDR-corrected $<0.05, \mathrm{Ks}>50$ at a cluster level and $\mathrm{p}$ $<0.001$ at a voxel level. In addition, we conducted a conjunction analysis across the sub-regions of hippocampus between the groups. The statistical threshold was set at $\mathrm{p}$ FDR-corrected $<0.05$, Ks $>50$ at a cluster level and $\mathrm{p}_{\text {FWE-corrected }}<0.05$ at a voxel level.

In order to explore the relationship between the altered FC and patients' impaired cognitive functions, the Functional Connectivity (CONN) Toolbox (http://web.mit.edu/swg/software.htm) was used. Regions of interest (ROIs) were defined based on the seed-based functional connectivity results (conjunction analysis results, see Fig. 3). Five ROIs were used from the automated anatomical labelling (AAL) template (Rolls et al., 2020) including supramarginal gyrus (anterior and posterior), angular gyrus, superior parietal lobe, and cerebellum (Fig. 4). Pre-processed images were entered to the toolbox with the covariates (age, gender, and the years of education). The sub-regions of hippocampus were also included as ROIs. ROI-to-ROI analysis was performed between the hippocampal sub-regions and ROIs by calculating the bivariate correlation between each pair of ROIs. Then, correlation analysis was conducted to link the FC changes between ROIs and individual's impaired memory function, accounting for age, gender, and the years of education ( $\mathrm{p}$ FDR-corrected $<0.05$ ).

\section{Results}

\subsection{Demographics, clinical, and cognitive scores}

Table 2 summarizes the results of demographics, clinical and cognitive scores. There was no age difference between the patients and control groups ( $p>0.7)$. However, there was a significant difference in the years of education $(\mathrm{t}=-2.40, \mathrm{p}=0.021)$ and gender $\left(\chi^{2}=6.35, \mathrm{p}=\right.$ 0.017 ) between the two groups.

The FSRP, Barthel, MoCA and HADS scores were significantly different between two groups (FSRP: $\mathrm{t}=2.90, \mathrm{p}=0.006$; Barthel: $\mathrm{t}=$ $-2.94, \mathrm{p}=0.007$; MoCA: $\mathrm{t}=-2.73, \mathrm{p}=0.009$; HADS Anxiety: $\mathrm{t}=1.91, \mathrm{p}$ $=0.065$; HADS Anxiety: $\mathrm{t}=5.84, \mathrm{p}<0.001$ ).

The BCoS scores revealed that the stroke patients had impairments in their memory and language domains compared to the controls. In the memory domain, the stroke group scored lower in the immediate free recall $\left(\mathrm{F}_{4,29}=8.14, \mathrm{p}=0.008\right)$, delayed free recall $\left(\mathrm{F}_{4,28}=5.08, \mathrm{p}=\right.$ $0.033)$, and task recognition $\left(\mathrm{F}_{4,25}=6.24, \mathrm{p}=0.019\right)$ relative to the control group. In the language domain, the patients with stroke showed worse performance in picture naming $\left(\mathrm{F}_{4,29}=4.54, \mathrm{p}=0.042\right)$, sentence $\left(\mathrm{F}_{4,29}=8.36, \mathrm{p}=0.007\right)$ and non-word reading $\left(\mathrm{F}_{4,28}=14.40, \mathrm{p}\right.$ $<0.001)$ compared with the control group. The patients also scored lower in Complex Figure Copy compared to the controls $\left(\mathrm{F}_{4}, 26=5.95, \mathrm{p}\right.$ $=0.022$ ). There was no significant difference in the other domains (Fs $<$ 0.001, ps > 0.97).

\subsection{Functional connectivity results}

Seed-based functional connectivity analysis is displayed in the Fig. 3 and Table 3. The overall results revealed decreased hippocampal FC with the supramarginal gyrus (SMG) and angular gyrus (AG), and increased FC with the cerebellum in the stroke group compared to the control group. Additionally, the patients showed FC reduction between CA2-supplementary motor area and between DG-right inferior occipital gyrus.

In order to find the overlapping areas across the FC of the hippocampal subfields, a conjunction analysis was conducted. The results demonstrated that relative to the controls, FC between the hippocampus-SMG and hippocampus-AG decreased in the stroke group, while FC between the hippocampus and cerebellum increased.

\subsection{The relationship between the altered FC and impaired cognitive functions in patients}

We explored the relationship between the altered FC found in the stroke group and their cognitive scores (Fig. 4). The FC between the hippocampal sub-regions and ROIs (anterior SMG: aSMG, posterior SMG: pSMG, AG, and cerebellum) were extracted and correlated with the impaired memory function (immediate free recall, and delayed free recall, see Table 1), accounting for age, gender, and the years of education.

The analysis revealed that the delayed free recall score in the stroke

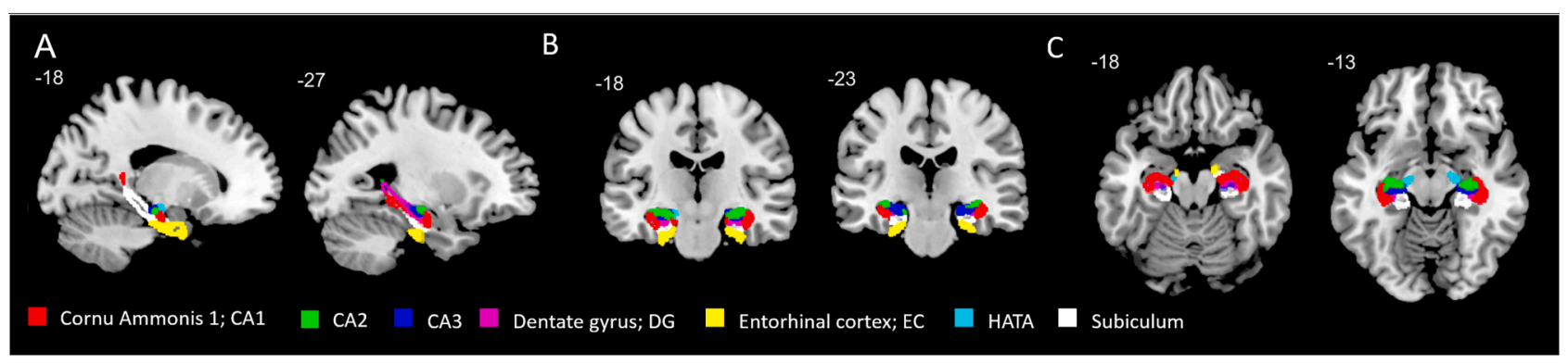

Fig. 2. The subfields of hippocampus. 
Table 2

Demographic information, clinical and cognitive scores.

\begin{tabular}{|c|c|c|c|c|}
\hline & $\mathrm{HC}$ & IS & Statistics & $\mathrm{p}$ value \\
\hline & $(\mathrm{n}=16)$ & $(\mathrm{n}=33)$ & & \\
\hline \multicolumn{5}{|l|}{$\begin{array}{l}\text { Demographics: mean } \\
\text { (SD) }\end{array}$} \\
\hline Gender, male/female & $5 / 9$ & $25 / 7$ & $\chi^{2}=6.35$ & $0.017^{*}$ \\
\hline Age & $\begin{array}{l}60.38 \\
(9.33) \\
(n=13)\end{array}$ & $\begin{array}{l}62.27 \\
(13.02) \\
(n=33)\end{array}$ & $\mathrm{t}=0.48$ & 0.637 \\
\hline Education, year & $\begin{array}{l}14.61 \\
(3.09) \\
(n=13)\end{array}$ & $\begin{array}{l}12.36 \\
(2.67) \\
(\mathrm{n}=28)\end{array}$ & $\mathrm{t}=-2.40$ & $0.021^{*}$ \\
\hline \multicolumn{5}{|l|}{ Clinical scales: mean (SD) } \\
\hline FSRP & $\begin{array}{l}12.61 \\
(12.26) \\
(\mathrm{n}=13)\end{array}$ & $\begin{array}{l}25.63 \\
(14.13) \\
(\mathrm{n}=32)\end{array}$ & $\mathrm{t}=2.90$ & $0.006^{* *}$ \\
\hline HADS Anxiety & $\begin{array}{l}2.50(1.76) \\
(\mathrm{n}=6)\end{array}$ & $\begin{array}{l}6.14(4.54) \\
(\mathrm{n}=29)\end{array}$ & $\mathrm{t}=1.91$ & 0.065 \\
\hline HADS Depression & $\begin{array}{l}1.00(0.89) \\
(\mathrm{n}=6)\end{array}$ & $\begin{array}{l}5.45(3.84) \\
(\mathrm{n}=29)\end{array}$ & $t=5.55$ & $\begin{array}{l}< \\
0.001 * * *\end{array}$ \\
\hline Barthel & $\begin{array}{l}20.00(0) \\
(n=6)\end{array}$ & $\begin{array}{l}18.38 \\
(2.97) \\
(\mathrm{n}=29)\end{array}$ & $\mathrm{t}=-2.94$ & $0.007^{* *}$ \\
\hline MoCA & $\begin{array}{l}26.57 \\
(2.30) \\
(n=7)\end{array}$ & $\begin{array}{l}21.36 \\
(4.89) \\
(n=33)\end{array}$ & $\mathrm{t}=-2.73$ & $0.009 * *$ \\
\hline NIHSS & N/A & $\begin{array}{l}5.78(5.66) \\
(\mathrm{n}=23)\end{array}$ & & \\
\hline BCoS scores: mean (SD) & & & $\mathrm{F}$ & \\
\hline \multicolumn{5}{|l|}{ Attention } \\
\hline Apple cancellation & $48.2(1.8)$ & $47.8(3.6)$ & 0.31 & 0.580 \\
\hline Left visual bilateral & $8.0(0)$ & $7.8(0.6)$ & 0.17 & 0.686 \\
\hline Right visual bilateral & $8.0(0)$ & $7.7(1.5)$ & 0.00 & 0.975 \\
\hline Left tactile bilateral & $8.0(0)$ & $7.8(0.4)$ & 1.06 & 0.314 \\
\hline Right tatile bilateral & $8.0(0)$ & $7.9(1.8)$ & 0.05 & 0.824 \\
\hline $\begin{array}{l}\text { Rule finding and } \\
\text { switching }\end{array}$ & $11.7(3.0)$ & $10.4(3.9)$ & 0.28 & 0.600 \\
\hline $\begin{array}{l}\text { Auditory attention } \\
\text { accuracy }\end{array}$ & $53.1(1.3)$ & $51.3(4.9)$ & 1.28 & 0.270 \\
\hline \multicolumn{5}{|l|}{ Memory } \\
\hline Personal information & $8(0)$ & $7.7(1.5)$ & 0.04 & 0.840 \\
\hline Time and space & $5.9(0.3)$ & $5.7(1.2)$ & 0.30 & 0.590 \\
\hline Immediate free recall & $9.2(1.8)$ & $6.6(3.1)$ & 8.14 & $0.008^{* *}$ \\
\hline Immediate recognition & $13.6(1.8)$ & $12.8(1.5)$ & 0.51 & 0.605 \\
\hline Delayed free recall & $10.6(1.6)$ & $7.9(3.3)$ & 5.08 & $0.033^{*}$ \\
\hline Delayed recognition & $13.5(1.5)$ & $12.5(1.9)$ & 0.77 & 0.388 \\
\hline Task recognition & $9.9(0.2)$ & $9.4(0.8)$ & 6.24 & $0.019^{*}$ \\
\hline Figure copy & $46.0(2.1)$ & $43.3(3.0)$ & 5.95 & $0.022^{*}$ \\
\hline \multicolumn{5}{|l|}{ Language } \\
\hline Picture naming & $13.5(0.9)$ & $11.8(3.1)$ & 4.54 & $0.042^{*}$ \\
\hline Sentence construction & $7.9(0.5)$ & $7.4(1.6)$ & 0.42 & 0.520 \\
\hline $\begin{array}{l}\text { Sentence reading } \\
\text { (accuracy) }\end{array}$ & $39.9(7.2)$ & $39.9(7.0)$ & 0.23 & 0.933 \\
\hline $\begin{array}{l}\text { Sentence reading } \\
\text { (second) }\end{array}$ & $13.7(3.6)$ & $23.0(11.7)$ & 8.36 & $0.007 * *$ \\
\hline $\begin{array}{l}\text { Nonword reading } \\
\text { (accuracy) }\end{array}$ & $4.9(2.1)$ & $4.8(1.5)$ & 0.48 & 0.857 \\
\hline $\begin{array}{l}\text { Nonword reading } \\
\text { (second) }\end{array}$ & $5.8(1.1)$ & $13.5(8.3)$ & 14.40 & $0.001 * * *$ \\
\hline Word writing & $4.7(0.8)$ & $3.5(1.4)$ & 12.71 & $0.002^{* *}$ \\
\hline \multicolumn{5}{|l|}{ Number } \\
\hline Number reading & $9(0)$ & $8.5(0.7)$ & 3.36 & 0.078 \\
\hline Number writing & $4.9(0.4)$ & $4.8(0.8)$ & 0.05 & 0.820 \\
\hline Calculation & $3.4(1.1)$ & $3.3(0.9)$ & 1.79 & 0.190 \\
\hline \multicolumn{5}{|l|}{ Praxis } \\
\hline Multiple object use & $11.9(0.3)$ & $11.8(0.6)$ & 0.77 & 0.440 \\
\hline Gesture prouction & $11.8(0.6)$ & $11.2(1.4)$ & 1.40 & 0.150 \\
\hline Gesture recognition & $5.8(0.6)$ & $5.7(0.7)$ & 0.28 & 0.770 \\
\hline
\end{tabular}

IS: ischemic stroke patient, HC: healthy control, NHISS: National Institute of Health Stroke Scale, FSRP: Framingham stroke risk profile, HADS: hospital anxiety and depression scale, MoCA: Montreal cognitive assessment, BCoS: Birmingham cognitive screen. N/A: not applicable. ${ }^{*} \mathrm{p}<0.05,{ }^{* *} \mathrm{p}<0.01$, ${ }^{* * *} \mathrm{p}$ $<0.001$

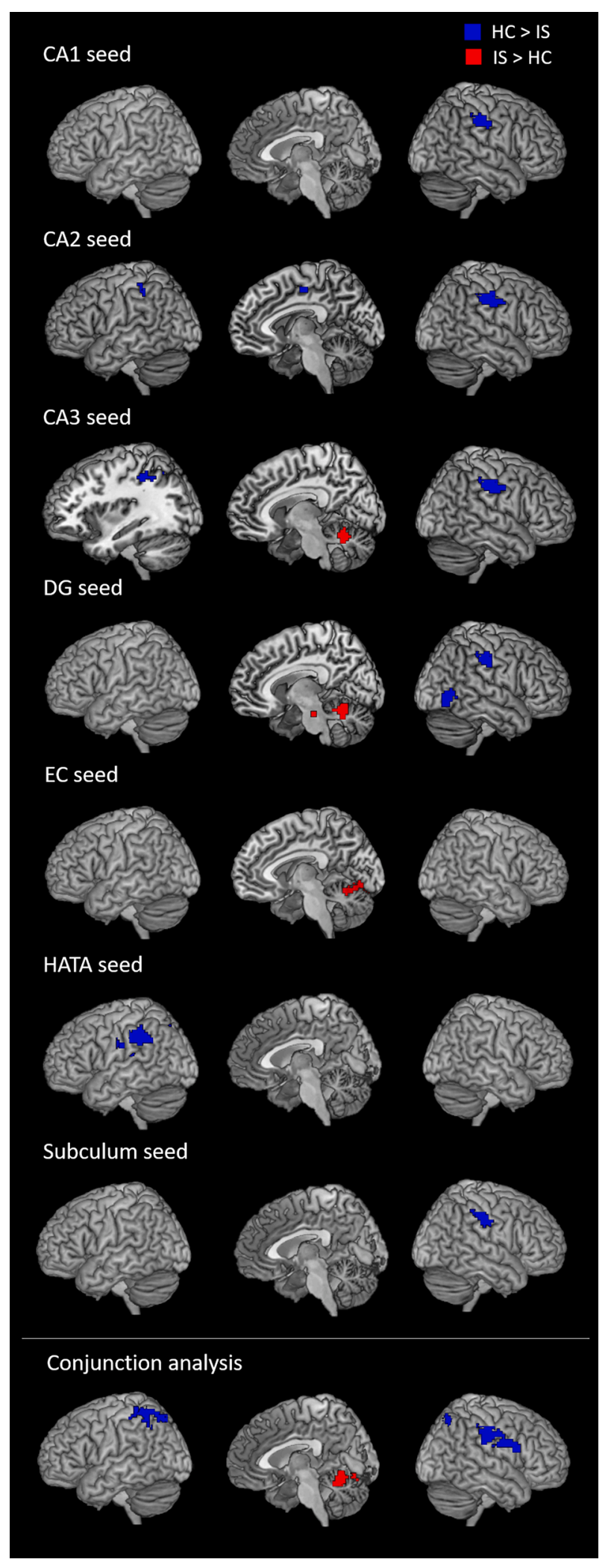

Fig. 3. The results of functional connectivity pattern of hippocampal subfields.

patients was negatively correlated with the CA1-left AG FC $(r=-0.51, \mathrm{p}$ FDR-corrected $=0.025)$ and DG-left AG FC $\left(r=-0.45, p_{\text {FDR-corrected }}=0.06\right)$. The more decreased FC in the CA1-left AG and DG-left AG in the patients, the better score in the delayed free recall was observed. The stroke group showed a significant correlation between the EC-left aSMG 
Table 3

The results of seed-based FC analysis.

\begin{tabular}{|c|c|c|c|c|c|c|c|}
\hline & \multirow[t]{2}{*}{ Contrast } & \multirow[t]{2}{*}{ Cluster region } & \multirow[t]{2}{*}{ Cluster extent } & \multicolumn{3}{|c|}{ Peak MNI coordniate } & \multirow[t]{2}{*}{ Z score } \\
\hline & & & & $\mathrm{x}$ & $\mathrm{y}$ & $\mathrm{z}$ & \\
\hline \multirow{3}{*}{ CA1 } & $\mathrm{HC}>\mathrm{IS}$ & R SupraMarginal Gyrus & 272 & 60 & -27 & 39 & 4.61 \\
\hline & & R Postcentral Gyrus & & 60 & -15 & 36 & 3.16 \\
\hline & IS $>\mathrm{HC}$ & - & & & & & \\
\hline \multirow[t]{7}{*}{ CA2 } & $\mathrm{HC}>\mathrm{IS}$ & R SupraMarginal Gyrus & 676 & 54 & -27 & 42 & 4.48 \\
\hline & & R Postcentral Gyrus & & 54 & -18 & 42 & 4.44 \\
\hline & & R SupraMarginal Gyrus & & 42 & -33 & 42 & 3.98 \\
\hline & & L Superior Parietal Lobule & 416 & -21 & -57 & 48 & 3.88 \\
\hline & & L Inferior Parietal Lobule & & -39 & -39 & 48 & 3.77 \\
\hline & & L Inferior Parietal Lobule & & -51 & -30 & 39 & 3.73 \\
\hline & IS $>\mathrm{HC}$ & - & & & & & \\
\hline \multirow[t]{9}{*}{ CA3 } & $\mathrm{HC}>\mathrm{IS}$ & R SupraMarginal Gyrus & 386 & 51 & -30 & 39 & 4.89 \\
\hline & & R Postcentral Gyrus & & 57 & -21 & 42 & 4.36 \\
\hline & & R Postcentral Gyrus & & 42 & -30 & 42 & 4.35 \\
\hline & & L Postcentral Gyrus & 442 & -27 & -39 & 45 & 4.09 \\
\hline & & L Inferior Parietal Lobule & & -45 & -39 & 51 & 3.94 \\
\hline & & L Inferior Parietal Lobule & & -48 & -30 & 36 & 3.94 \\
\hline & IS $>$ HC & Cerebellum & 203 & -6 & -33 & -15 & 4.2 \\
\hline & & Cerebellum & & 9 & -54 & -18 & 3.98 \\
\hline & & Cerebellum & & 3 & -54 & -24 & 3.95 \\
\hline \multirow[t]{13}{*}{ DG } & $\mathrm{HC}>\mathrm{IS}$ & R Inferior Temporal Gyrus & 133 & 54 & -66 & -3 & 4.68 \\
\hline & & R Inferior Temporal Gyrus & & 48 & -69 & -12 & 4.06 \\
\hline & & R SupraMarginal Gyrus & 563 & 60 & -24 & 42 & 4.54 \\
\hline & & R SupraMarginal Gyrus & & 51 & -33 & 42 & 4.3 \\
\hline & & L Posterior-Medial Frontal & & 0 & -9 & 51 & 3.85 \\
\hline & & L Inferior Occipital Gyrus & 128 & -39 & -72 & -12 & 3.93 \\
\hline & & L Inferior Temporal Gyrus & & -45 & -66 & -6 & 3.62 \\
\hline & & L Inferior Temporal Gyrus & & -42 & -48 & -15 & 3.45 \\
\hline & & L Precuneus & 279 & -15 & -57 & 63 & 3.56 \\
\hline & & L Postcentral Gyrus & & -51 & -36 & 57 & 3.56 \\
\hline & IS $>$ HC & Cerebellum & 500 & 3 & -54 & -15 & 4.56 \\
\hline & & Cerebellum & & -6 & -30 & -15 & 4.39 \\
\hline & & Cerebellum & & 6 & -15 & -12 & 4.29 \\
\hline \multirow[t]{6}{*}{$\mathrm{EC}$} & $\mathrm{HC}>\mathrm{IS}$ & - & & & & & \\
\hline & IS $>\mathrm{HC}$ & R Inferior Occipital Gyrus & 91 & 30 & -93 & -3 & 3.99 \\
\hline & & R Inferior Occipital Gyrus & & 36 & -87 & -3 & 3.94 \\
\hline & & L Lingual Gyrus & 197 & -3 & -75 & -6 & 3.69 \\
\hline & & Cerebellum & & 9 & -60 & -15 & 3.59 \\
\hline & & Cerebellum & & 3 & -69 & -12 & 3.58 \\
\hline \multirow[t]{7}{*}{ HATA } & $\mathrm{HC}>$ IS & L Inferior Parietal Lobule & 500 & -30 & -57 & 39 & 4.63 \\
\hline & & L Inferior Parietal Sulcus & & -48 & -30 & 36 & 4.26 \\
\hline & & L SupraMarginal Gyrus & & -60 & -36 & 33 & 3.63 \\
\hline & & R SupraMarginal Gyrus & 253 & 54 & -18 & 27 & 3.9 \\
\hline & & R SupraMarginal Gyrus & & 48 & -30 & 39 & 3.78 \\
\hline & & R SupraMarginal Gyrus & & 63 & -21 & 30 & 3.56 \\
\hline & IS $>$ HC & - & & & & & \\
\hline \multirow[t]{3}{*}{ Subculum } & $\mathrm{HC}>\mathrm{IS}$ & R SupraMarginal Gyrus & 131 & 57 & -27 & 42 & 4.27 \\
\hline & & R Postcentral gyrus & & 57 & -15 & 36 & 3.28 \\
\hline & IS $>\mathrm{HC}$ & - & & & & & \\
\hline \multirow[t]{12}{*}{ Conjunction analysis } & $\mathrm{HC}>$ IS & R SupraMarginal Gyrus & 253 & 36 & -36 & 36 & Inf \\
\hline & & R SupraMarginal Gyrus & & 45 & -30 & 36 & 7.48 \\
\hline & & R Postcentral gyrus & & 60 & -21 & 36 & 7.22 \\
\hline & & L Angular Gyrus & 286 & -33 & -48 & 30 & 7.69 \\
\hline & & L Angular Gyrus & & -33 & -48 & 42 & 7.47 \\
\hline & & L Superior Parietal Lobule & & -27 & -72 & 51 & 7.09 \\
\hline & & R Angular Gyrus & 72 & 27 & -57 & 45 & 6.36 \\
\hline & & R Angular Gyrus & & 36 & -69 & 54 & 6.18 \\
\hline & & R Angular Gyrus & & 33 & -69 & 42 & 6.08 \\
\hline & IS $>\mathrm{HC}$ & Cerebellum & 129 & -3 & -57 & -9 & Inf \\
\hline & & Cerebellum & & 3 & -54 & -18 & 7.63 \\
\hline & & Cerebellum & & 0 & -72 & -9 & 6.65 \\
\hline
\end{tabular}

CA: Corne Ammonis; DG: Dentate Gyrus; EC: Enthorhinal Cortex; IS: Ischemic stroke; HC: healthy control.

$\mathrm{FC}$ and immediate free recall score $(\mathrm{r}=0.42, \mathrm{p}$ FDR-corrected $=0.049)$. The patients with stronger FC in the EC-left aSMG performed better in the immediate free recall. The control group showed no significant correlations (CA1-left AG \& delayed free recall: $\mathrm{r}=-0.49, \mathrm{p}$ FDR-corrected $=$ 0.07, DG-left AG \& delayed free recall: $r=-0.46, \mathrm{p}$ FDR-corrected $=1$, ECleft aSMG \& immediate free recall: $r=0.36$, p FDR-corrected $=1$ ) (Fig. S1).

\section{Discussion}

The current study examined the altered FC of the hippocampal subfields in patients with post-stroke cognitive impairment. The altered FC of hippocampal subfields was mainly located in the inferior parietal lobule (IPL) and cerebellum. Furthermore, the degree of the functional 


\section{Regions of interest}

$D G-I . A G$

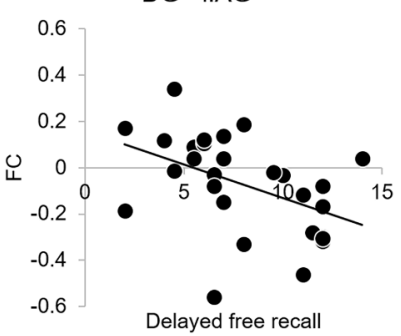

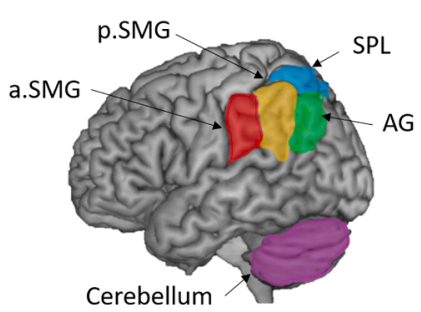

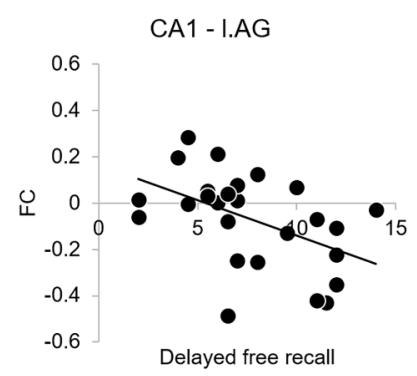

EC - I.aSMG

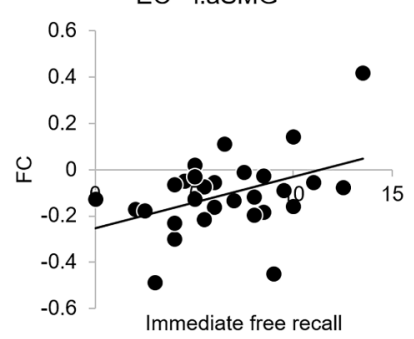

Fig. 4. The relationship between the functional connectivity of hippocampal subfields and memory function in the patients. aSMG: anterior supramarginal gyrus, pSMG: posterior supramarginal gyrus, AG: angular gyrus, SPL: superior parietal lobe.

connectivity changes between the hippocampal subfields and IPL was associated with post-stroke cognitive impairment involving memory. These findings provide novel insights into our understanding of cognitively impaired patients following an ischemic stroke (post-stroke cognitive impairment), as compared with age-matched healthy controls.

The novel finding of the current study is decreased FC between the hippocampal subfields and IPL (supramarginal gyrus: SMG and angular gyrus: AG) after ischemic stroke, compared with the control group. The SMG is the anterior part of the IPL and associated with visual attention (Chambers et al., 2004; Stevens et al., 2005), working memory (Sommer et al., 2006; Uncapher and Wagner, 2009), motion perception (Martinez-Trujillo et al., 2007), and, phonological (Humphreys and Ralph, 2015; Oberhuber et al., 2016) and semantic processing (Price, 2010; Raposo et al., 2006). Stroke patients with left SMG lesions demonstrated impairments in their verbal memory function (Beeson et al., 1993; Caplan et al., 1995). A study with amnestic MCI patients investigated the hippocampal FC compared to controls and reported altered hippocampal FC in frontal, temporal, and parietal lobe such as the SMG (Bai et al., 2009). Similarly, we found that post-stroke memory impairment was associated with functional connectivity alterations between the hippocampal subfields and SMG. These hippocampal FC changes might be the early sign of functional abnormalities in the episodic memory system (Bai et al., 2009). Furthermore, the patients in our cohort with more decoupling in the hippocampus-SMG FC performed worse in immediate free recall when compared with the control group. Our findings suggest that the dysfunctional relationship between the hippocampus and SMG may contribute to post-stroke memory impairment and could be a potential neural marker during subacute ischaemic stroke.

AG is the posterior part of the IPL and a cross-modal hub (Grayson et al., 2014; Seghier, 2013) supported by its widespread structural and functional connection with various brain regions (Seghier et al., 2010). Thus, the function of the AG is diverse ranging from attention, spatial cognition, language, semantic processing, and social cognition to episodic memory (Binder et al., 2009; Humphreys and Ralph, 2015; Price et al., 2015; Seghier, 2013; Vincent et al., 2006). In addition, functional connection of the AG reveals that the AG is a key region of the default mode network (DMN) as well as a connector hub across the DMN, salience, executive control, and attention networks (Humphreys et al., 2015; Igelstrom and Graziano, 2017; Xu et al., 2016). Newhart et al (2012) studied patients with acute ischemia and showed the working memory deficit in the patients with the AG lesion. Transcranial magnetic stimulation (TMS) studies also demonstrated the causal role of the left AG in episodic memory by delivering inhibitory protocols over the left AG (e.g., temporarily disrupting ongoing processing at the target brain region) (Bonnici et al., 2018; Thakral et al., 2017). Another study of post-stroke cognitive impairment (Tuladhar et al., 2013) reported a decreased connectivity within the DMN including the hippocampus compared to controls. Snaphaan et al (2009) examined the working memory function in stroke patients and reported that hippocampal activation was reduced during 2-back working memory task. These findings highlight the role of the AG and the interaction between the hippocampus and AG in episodic memory function. Similarly, we found that patients with ischaemic stroke had lower FC between the hippocampal subfields and AG. Further, the degree of memory impairment after stroke correlated with the level of the FC alterations. Taken together, our findings suggest the dysfunctional connectivity of hippocampus underlying memory impairment after ischemic stroke.

Emerging evidence from functional neuroimaging, neurophysiology and computational modelling supports the importance of interaction between the hippocampus, medial temporal cortex, IPL, precunues, and prefrontal cortex for memory function (Clower et al., 2001; Cooper and Ritchey, 2019; Geib et al., 2017; King et al., 2015; Simons and Spiers, 2003). Any lesion or disconnection in this network may result in memory dysfunction, which can be found in stroke and dementia patients (Bai et al., 2009; Beeson et al., 1993; Caplan et al., 1995; den Heijer et al., 2010; Elcombe et al., 2014; La Joie et al., 2014; Newhart et al., 2012; Snaphaan et al., 2009; Tuladhar et al., 2013). Here, our study highlights the decreased hippocampal-IPL connectivity related to memory deficits in post-stroke cognitive impairment.

We found an increased FC between the hippocampal subfields and cerebellum. The cerebellum has been related to motor control, cognition, and emotion (Glickstein, 2007; Strick et al., 2009). Furthermore, the cerebellum is involved in storing formed memory, and known to show an increased activation during memory tasks (Groussard et al., 2010; Kuper et al., 2016). Cerebellar-hippocampal interaction is associated with various cognitive functions such as spatial and temporal processing (For a reivew, see Yu and Krook-Magnuson, 2015) and a few studies have reported increased cerebellar-hippocampal FC during a finger tapping task (Onuki et al., 2015), eye blink conditioning (Singer, 1999), and spatial navigation (Rochefort et al., 2011). These studies indicate the importance of cerebellum and the cerebellar-hippocampal connection for cognitive tasks. Previously, Yang et al (Yang et al., 2014) showed increased hippocampal FC with insula, medial frontal gyrus, superior temporal gyrus, and cerebellum in patients with unilateral infarction of the basal ganglia. Thus, the enhanced hippocampalcerebellar FC in our study might be driven from a potential compensatory mechanism after ischaemic stroke.

Several limitations in this study need to be considered. First, the patients differed from the controls in sex and years of education. Although we included them as covariates in all of our analysis, future studies are required with better matched and higher number of healthy controls. Second, the patients had higher depression score than the controls. The post-stroke depression has been reported to alter FC in the DMN, cognitive control network and affective network (Lassalle-Lagadec et al., 2012; Zhang et al., 2018). To confirm our findings, we reanalysed our data with HADS depression scores as an additional covariate. The results replicated our initial findings - the decreased hippocampal-IPL connectivity and the increased hippocampalcerebellum connectivity in the patients. Thus, our results were not affected by the depression in the patient group. The inclusion of patients with a left, right, or bilateral lesion is another limitation of our study. Lesion location is an important factor to determine outcome after stroke (Beloosesky et al., 1995). As language functions are lateralized to the left hemisphere, damage to classic perisylvian language areas of the left hemisphere shows considerable language impairment (Damasio, 1992). 
To examine the effect of the laterality of the lesions, we re-analysed our data with the lesion site as a covariate and the results replicated our original findings. Although our results were not influenced by the lesion location, future studies are needed to elucidate the relationship between the lesion location, cognitive impairment, and functional connectivity in ischemic stroke. Further, we did not consider the effects of hemodynamic changes caused by stroke. As FC changes may reflect altered hemodynamic responses following stroke (Siegel et al., 2016; Zhao et al., 2018), our results should be interpreted cautiously.

Clinically, our finding could contribute to the identification of patients with post-stroke cognitive impairment due to the altered hippocampal FC patterns, before emerging irreversible hippocampal atrophy. It might have significant implications in diagnostics because a large proportion of stroke patients with cognitive impairment are at increased risk of delayed hippocampal atrophy and developing post-stroke dementia (Rockwood et al., 2000; Wentzel et al., 2001), which is three times higher than the risk of a recurrent stroke (Yokota et al., 2004).

\section{Funding}

AAH was the Principal Investigator of the Hippocampal Pathology in Post-Stroke Cognitive Impairment (HiPPSCI) Study (Co-Investigators: PR, DPA, MW, Don Sims, Sissi Ispoglou, Vijay Sawlani, and Tom Hayton). The study received funding from the Stroke Association, UK (TSA PGF 2016-02) awarded to RL for her PhD that was supervised by PR and AAH. HiPPSCI was co-funded by the Midland Neurosciences Teaching and Research Fund. AAH is currently funded by the Medical Research Council, UK (grant MR/T005580/1)

\section{CRediT authorship contribution statement}

JeYoung Jung: Data curation, Formal analysis, Investigation, Methodology, Visualization, Writing - original draft, Writing - review \& editing. Rosanna Laverick: Conceptualization, Data curation, Investigation, Writing - original draft, Writing - review \& editing. Kurdow Nader: Methodology, Formal analysis, Writing - review \& editing. Thomas Brown: Methodology, Formal analysis, Visualization. Haley Morris: Methodology, Formal analysis. Martin Wilson: Methodology. Dorothee P. Auer: Conceptualization, Writing - original draft, Writing review \& editing. Pia Rotshtein: Conceptualization, Investigation, Writing - original draft, Writing - review \& editing. Akram A. Hosseini: Conceptualization, Formal analysis, Investigation, Writing - original draft, Writing - review \& editing.

\section{Declaration of Competing Interest}

The authors declare that they have no known competing financial interests or personal relationships that could have appeared to influence the work reported in this paper.

\section{Acknowledgement}

We would like to acknowledge study co-investigators not listed as coauthors, the research nurses at Sandwell General Hospital and Queen Elizabeth Hospital Birmingham, and the Birmingham University Imaging Centre (now the Centre for Human Brain Health) for supporting the study. Additionally, Rachel Evans and students; Emily Todd and Alicia Northall for the support in data collection.

\section{Appendix A. Supplementary data}

Supplementary data to this article can be found online at https://doi. org/10.1016/j.nicl.2021.102742.

\section{References}

Al-Qazzaz, N.K., Ali, S.H., Ahmad, S.A., Islam, S., Mohamad, K., 2014. Cognitive impairment and memory dysfunction after a stroke diagnosis: a post-stroke memory assessment. Neuropsychiatr Dis Treat 10, 1677-1691.

Amunts, K., Kedo, O., Kindler, M., Pieperhoff, P., Mohlberg, H., Shah, N.J., Habel, U., Schneider, F., Zilles, K., 2005. Cytoarchitectonic mapping of the human amygdala, hippocampal region and entorhinal cortex: intersubject variability and probability maps. Anat Embryol (Berl) 210, 343-352.

Anderson, J.S., Druzgal, T.J., Lopez-Larson, M., Jeong, E.K., Desai, K., YurgelunTodd, D., 2011. Network anticorrelations, global regression, and phase-shifted soft tissue correction. Hum Brain Mapp 32, 919-934.

Ashburner, J., 2007. A fast diffeomorphic image registration algorithm. Neuroimage 38, 95-113.

Bai, F., Zhang, Z., Watson, D.R., Yu, H., Shi, Y., Yuan, Y., Zang, Y., Zhu, C., Qian, Y., 2009. Abnormal functional connectivity of hippocampus during episodic memory retrieval processing network in amnestic mild cognitive impairment. Biol Psychiatry 65, 951-958.

Baldassarre, A., Ramsey, L.E., Siegel, J.S., Shulman, G.L., Corbetta, M., 2016. Brain connectivity and neurological disorders after stroke. Curr Opin Neurol 29, 706-713.

Barnes, J., Ourselin, S., Fox, N.C., 2009. Clinical application of measurement of hippocampal atrophy in degenerative dementias. Hippocampus 19, 510-516.

Beeson, P.M., Bayles, K.A., Rubens, A.B., Kaszniak, A.W., 1993. Memory impairment and executive control in individuals with stroke-induced aphasia. Brain Lang 45, 253-275.

Beloosesky, Y., Streifler, J.Y., Burstin, A., Grinblat, J., 1995. The importance of brain infarct size and location in predicting outcome after stroke. Age Ageing 24, 515-518.

Berron, D., Schutze, H., Maass, A., Cardenas-Blanco, A., Kuijf, H.J., Kumaran, D., Duzel, E., 2016. Strong Evidence for Pattern Separation in Human Dentate Gyrus. J Neurosci 36, 7569-7579.

Bickerton, W.L., Demeyere, N., Francis, D., Kumar, V., Remoundou, M., Balani, A., Harris, L., Williamson, J., Lau, J.K., Samson, D., Riddoch, M.J., Humphreys, G.W., 2015. The BCoS cognitive profile screen: Utility and predictive value for stroke. Neuropsychology 29, 638-648.

Binder, J.R., Desai, R.H., Graves, W.W., Conant, L.L., 2009. Where is the semantic system? A critical review and meta-analysis of 120 functional neuroimaging studies. Cereb Cortex 19, 2767-2796.

Bird, C.M., Burgess, N., 2008. The hippocampus and memory: insights from spatial processing. Nat Rev Neurosci 9, 182-194.

Blum, S., Luchsinger, J.A., Manly, J.J., Schupf, N., Stern, Y., Brown, T.R., DeCarli, C., Small, S.A., Mayeux, R., Brickman, A.M., 2012. Memory after silent stroke: hippocampus and infarcts both matter. Neurology 78, 38-46.

Bonnici, H.M., Cheke, L.G., Green, D.A.E., FitzGerald, T., Simons, J.S., 2018. Specifying a Causal Role for Angular Gyrus in Autobiographical Memory. J Neurosci 38, 10438-10443.

Campbell, B.C.V., De Silva, D.A., Macleod, M.R., Coutts, S.B., Schwamm, L.H., Davis, S. M., Donnan, G.A., 2019. Ischaemic stroke. Nat Rev Dis Primers 5, 70.

Caplan, D., Gow, D., Makris, N., 1995. Analysis of lesions by MRI in stroke patients with acoustic-phonetic processing deficits. Neurology 45, 293-298.

Carter, A.R., Astafiev, S.V., Lang, C.E., Connor, L.T., Rengachary, J., Strube, M.J., Pope, D.L., Shulman, G.L., Corbetta, M., 2010. Resting interhemispheric functional magnetic resonance imaging connectivity predicts performance after stroke. Ann Neurol 67, 365-375.

Chambers, C.D., Payne, J.M., Stokes, M.G., Mattingley, J.B., 2004. Fast and slow parietal pathways mediate spatial attention. Nat. Neurosci. 7, 217-218.

Chen, G., Ward, B.D., Xie, C., Li, W., Wu, Z., Jones, J.L., Franczak, M., Antuono, P., Li, S. J., 2011. Classification of Alzheimer disease, mild cognitive impairment, and normal cognitive status with large-scale network analysis based on resting-state functional MR imaging. Radiology 259, 213-221.

Clower, D.M., West, R.A., Lynch, J.C., Strick, P.L., 2001. The inferior parietal lobule is the target of output from the superior colliculus, hippocampus, and cerebellum. J Neurosci 21, 6283-6291.

Cooper, R.A., Ritchey, M., 2019. Cortico-hippocampal network connections support the multidimensional quality of episodic memory. Elife 8.

Damasio, A.R., 1992. Aphasia. N Engl J Med 326, 531-539.

den Heijer, T., van der Lijn, F., Koudstaal, P.J., Hofman, A., van der Lugt, A., Krestin, G. P., Niessen, W.J., Breteler, M.M., 2010. A 10-year follow-up of hippocampal volume on magnetic resonance imaging in early dementia and cognitive decline. Brain 133, 1163-1172.

Eickhoff, S.B, Stephan, K.E., Mohlberg, H., Grefkes, C., Fink, G.R., Amunts, K., Zilles, K., 2005. A new SPM toolbox for combining probabilistic cytoarchitectonic maps and functional imaging data. Neuroimage 25, 1325-1335.

Elcombe, E.L., Lagopoulos, J., Mowszowski, L., Diamond, K., Paradise, M., Hickie, I.B., Lewis, S.J., Naismith, S.L., 2014. Clinical and Cognitive Correlates of Structural Hippocampal Change in "At-Risk" Older Adults. J Geriatr Psychiatry Neurol 27, 67-76.

Fish, J., 2011. Rankin Scale. Springer, New York, NY.

Friston, K.J., Williams, S., Howard, R., Frackowiak, R.S., Turner, R., 1996. Movementrelated effects in fMRI time-series. Magn Reson Med 35, 346-355.

Garrity, A.G., Pearlson, G.D., McKiernan, K., Lloyd, D., Kiehl, K.A., Calhoun, V.D., 2007. Aberrant "default mode" functional connectivity in schizophrenia. Am J Psychiatry $164,450-457$.

Geib, B.R., Stanley, M.L., Dennis, N.A., Woldorff, M.G., Cabeza, R., 2017. From hippocampus to whole-brain: The role of integrative processing in episodic memory retrieval. Hum Brain Mapp 38, 2242-2259. 
Gemmell, E., Bosomworth, H., Allan, L., Hall, R., Khundakar, A., Oakley, A.E., Deramecourt, V., Polvikoski, T.M., O'Brien, J.T., Kalaria, R.N., 2012. Hippocampa neuronal atrophy and cognitive function in delayed poststroke and aging-related dementias. Stroke 43, 808-814.

Glickstein, M., 2007. What does the cerebellum really do? Curr Biol 17, R824-827.

Golestani, A.M., Tymchuk, S., Demchuk, A., Goodyear, B.G., Group, V.-S., 2013. Longitudinal evaluation of resting-state FMRI after acute stroke with hemiparesis. Neurorehabil Neural Repair 27, 153-163.

Gorelick, P.B., Scuteri, A., Black, S.E., Decarli, C., Greenberg, S.M., Iadecola, C., Launer, L.J., Laurent, S., Lopez, O.L., Nyenhuis, D., Petersen, R.C., Schneider, J.A. Tzourio, C., Arnett, D.K., Bennett, D.A., Chui, H.C., Higashida, R.T., Lindquist, R., Nilsson, P.M., Roman, G.C., Sellke, F.W., Seshadri, S., Council, A.H.A.S., C.o.E., Prevention, C.o.C.N.C.o.C.R., Intervention, Council on Cardiovascular, S., Anesthesia,, 2011. Vascular contributions to cognitive impairment and dementia: a statement for healthcare professionals from the american heart association/american stroke association. Stroke 42, 2672-2713.

Grayson, D.S., Ray, S., Carpenter, S., Iyer, S., Dias, T.G., Stevens, C., Nigg, J.T., Fair, D.A., 2014. Structural and functional rich club organization of the brain in children and adults. PLoS ONE 9, e88297.

Grefkes, C., Fink, G.R., 2011. Reorganization of cerebral networks after stroke: new insights from neuroimaging with connectivity approaches. Brain 134, 1264-1276.

Grefkes, C., Fink, G.R., 2014. Connectivity-based approaches in stroke and recovery of function. Lancet Neurol 13, 206-216.

Greicius, M.D., Flores, B.H., Menon, V., Glover, G.H., Solvason, H.B., Kenna, H., Reiss, A. L., Schatzberg, A.F., 2007. Resting-state functional connectivity in major depression: abnormally increased contributions from subgenual cingulate cortex and thalamus. Biol Psychiatry 62, 429-437.

Groussard, M., Viader, F., Hubert, V., Landeau, B., Abbas, A., Desgranges, B., Eustache, F., Platel, H., 2010. Musical and verbal semantic memory: two distinct neural networks? Neuroimage 49, 2764-2773.

Henry, J.D., Crawford, J.R., 2004. A meta-analytic review of verbal fluency performance following focal cortical lesions. Neuropsychology 18, 284-295.

Herbert, V., Brookes, R.L., Markus, H.S., Morris, R.G., 2014. Verbal fluency in cerebral small vessel disease and Alzheimer's disease. J Int Neuropsychol Soc 20, 413-421.

Hodgetts, C.J., Voets, N.L., Thomas, A.G., Clare, S., Lawrence, A.D., Graham, K.S., 2017. Ultra-High-Field fMRI Reveals a Role for the Subiculum in Scene Perceptual Discrimination. J Neurosci 37, 3150-3159.

Humphreys, G., Bickerton, W.-L., Samson, D., Riddoch, M., 2012. BCoS Cognition Screen. Psychology Press, Hove, England.

Humphreys, G.F., Hoffman, P., Visser, M., Binney, R.J., Lambon Ralph, M.A., 2015. Establishing task- and modality-dependent dissociations between the semantic and default mode networks. Proc Natl Acad Sci U S A 112, 7857-7862.

Humphreys, G.F., Ralph, M.A., 2015. Fusion and Fission of Cognitive Functions in the Human Parietal Cortex. Cereb. Cortex 25, 3547-3560.

Igelstrom, K.M., Graziano, M.S.A., 2017. The inferior parietal lobule and temporoparietal junction: A network perspective. Neuropsychologia 105, 70-83.

King, D.R., de Chastelaine, M., Elward, R.L., Wang, T.H., Rugg, M.D., 2015. Recollectionrelated increases in functional connectivity predict individual differences in memory accuracy. J Neurosci 35, 1763-1772.

Kroll, H., Zaharchuk, G., Christen, T., Heit, J.J., Iv, M., 2017. Resting-State BOLD MRI for Perfusion and Ischemia. Top Magn Reson Imaging 26, 91-96.

Kuper, M., Kaschani, P., Thurling, M., Stefanescu, M.R., Burciu, R.G., Goricke, S., Maderwald, S., Ladd, M.E., Hautzel, H., Timmann, D., 2016. Cerebellar fMRI Activation Increases with Increasing Working Memory Demands. Cerebellum 15, 322-335.

La Joie, R., Landeau, B., Perrotin, A., Bejanin, A., Egret, S., Pelerin, A., Mezenge, F., Belliard, S., de La Sayette, V., Eustache, F., Desgranges, B., Chetelat, G., 2014 Intrinsic connectivity identifies the hippocampus as a main crossroad between Alzheimer's and semantic dementia-targeted networks. Neuron 81, 1417-1428.

Lassalle-Lagadec, S., Sibon, I., Dilharreguy, B., Renou, P., Fleury, O., Allard, M., 2012. Subacute default mode network dysfunction in the prediction of post-stroke depression severity. Radiology 264, 218-224.

Lee, M.H., Smyser, C.D., Shimony, J.S., 2013. Resting-state fMRI: a review of methods and clinical applications. AJNR Am J Neuroradiol 34, 1866-1872.

Lezak, M.D., 1976. Neuropsychological assessment. Oxford University Press, New York.

Lv, Y., Li, L., Song, Y., Han, Y., Zhou, C., Zhou, D., Zhang, F., Xue, Q., Liu, J., Zhao, L., Zhang, C., Han, X., 2019. The Local Brain Abnormalities in Patients With Transient Ischemic Attack: A Resting-State fMRI Study. Front Neurosci 13, 24.

Mahoney, F.I., Barthel, D.W., 1965. Functional Evaluation: The Barthel Index. Md State Med J 14, 61-65.

Martinez-Trujillo, J.C., Cheyne, D., Gaetz, W., Simine, E., Tsotsos, J.K., 2007. Activation of area MT/V5 and the right inferior parietal cortex during the discrimination of transient direction changes in translational motion. Cereb Cortex 17, 1733-1739.

Mueller, S.G., Laxer, K.D., Scanlon, C., Garcia, P., McMullen, W.J., Loring, D.W., Meador, K.J., Weiner, M.W., 2012. Different structural correlates for verbal memory impairment in temporal lobe epilepsy with and without mesial temporal lobe sclerosis. Hum Brain Mapp 33, 489-499.

Nasreddine, Z.S., Phillips, N.A., Bedirian, V., Charbonneau, S., Whitehead, V., Collin, I., Cummings, J.L., Chertkow, H., 2005. The Montreal Cognitive Assessment, MoCA: brief screening tool for mild cognitive impairment. J Am Geriatr Soc 53, 695-699.

Neunuebel, J.P., Knierim, J.J., 2014. CA3 retrieves coherent representations from degraded input: direct evidence for CA3 pattern completion and dentate gyrus pattern separation. Neuron 81, 416-427.

Newhart, M., Trupe, L.A., Gomez, Y., Cloutman, L., Molitoris, J.J., Davis, C., Leigh, R., Gottesman, R.F., Race, D., Hillis, A.E., 2012. Asyntactic comprehension, working memory, and acute ischemia in Broca's area versus angular gyrus. Cortex 48, 1288-1297.

Oberhuber, M., Hope, T.M.H., Seghier, M.L., Parker Jones, O., Prejawa, S., Green, D.W., Price, C.J., 2016. Four Functionally Distinct Regions in the Left Supramarginal Gyrus Support Word Processing. Cereb Cortex 26, 4212-4226.

Onuki, Y., Van Someren, E.J., De Zeeuw, C.I., Van der Werf, Y.D., 2015. Hippocampalcerebellar interaction during spatio-temporal prediction. Cereb Cortex 25, 313-321.

Ovadia-Caro, S., Margulies, D.S., Villringer, A., 2014. The value of resting-state functional magnetic resonance imaging in stroke. Stroke 45, 2818-2824.

Pan, X., Chen, H., Bickerton, W.L., Lau, J.K., Kong, A.P., Rotshtein, P., Guo, A., Hu, J., Humphreys, G.W., 2015. Preliminary findings on the reliability and validity of the Cantonese Birmingham Cognitive Screen in patients with acute ischemic stroke. Neuropsychiatr Dis Treat 11, 2377-2390.

Power, J.D., Mitra, A., Laumann, T.O., Snyder, A.Z., Schlaggar, B.L., Petersen, S.E., 2014. Methods to detect, characterize, and remove motion artifact in resting state fMRI. Neuroimage 84, 320-341.

Price, A.R., Bonner, M.F., Peelle, J.E., Grossman, M., 2015. Converging evidence for the neuroanatomic basis of combinatorial semantics in the angular gyrus. J Neurosci 35, 3276-3284.

Price, C.J., 2010. The anatomy of language: a review of 100 fMRI studies published in 2009. Year in Cognitive Neuroscience 2010 (1191), 62-88.

Puig, J., Blasco, G., Alberich-Bayarri, A., Schlaug, G., Deco, G., Biarnes, C., NavasMarti, M., Rivero, M., Gich, J., Figueras, J., Torres, C., Daunis, I.E.P., OramasRequejo, C.L., Serena, J., Stinear, C.M., Kuceyeski, A., Soriano-Mas, C., Thomalla, G., Essig, M., Figley, C.R., Menon, B., Demchuk, A., Nael, K., Wintermark, M., Liebeskind, D.S., Pedraza, S., 2018. Resting-State Functional Connectivity Magnetic Resonance Imaging and Outcome After Acute Stroke. Stroke 49, 2353-2360.

Raposo, A., Moss, H.E., Stamatakis, E.A., Tyler, L.K., 2006. Repetition suppression and semantic enhancement: an investigation of the neural correlates of priming. Neuropsychologia 44, 2284-2295.

Rochefort, C., Arabo, A., Andre, M., Poucet, B., Save, E., Rondi-Reig, L., 2011. Cerebellum shapes hippocampal spatial code. Science 334, 385-389.

Rockwood, K., Howard, K., MacKnight, C., Darvesh, S., 1999. Spectrum of disease in vascular cognitive impairment. Neuroepidemiology 18, 248-254.

Rockwood, K., Wentzel, C., Hachinski, V., Hogan, D.B., MacKnight, C., McDowell, I., 2000. Prevalence and outcomes of vascular cognitive impairment. Vascular Cognitive Impairment Investigators of the Canadian Study of Health and Aging. Neurology 54, 447-451.

Rolls, E.T., Huang, C.C., Lin, C.P., Feng, J., Joliot, M., 2020. Automated anatomical labelling atlas 3. Neuroimage 206, 116189.

Rosner, B.A., 2006. Fundamentals of Biostatistics, 6th Edn. Thomson-Brooks/Cole, Belmont, CA.

Rossler, M., Zarski, R., Bohl, J., Ohm, T.G., 2002. Stage-dependent and sector-specific neuronal loss in hippocampus during Alzheimer's disease. Acta Neuropathol 103, 363-369.

Satterthwaite, T.D., Elliott, M.A., Gerraty, R.T., Ruparel, K., Loughead, J., Calkins, M.E., Eickhoff, S.B., Hakonarson, H., Gur, R.C., Gur, R.E., Wolf, D.H., 2013. An improved framework for confound regression and filtering for control of motion artifact in the preprocessing of resting-state functional connectivity data. Neuroimage 64, 240-256.

Seghier, M.L., 2013. The angular gyrus: multiple functions and multiple subdivisions. Neuroscientist 19, 43-61.

Seghier, M.L., Fagan, E., Price, C.J., 2010. Functional subdivisions in the left angular gyrus where the semantic system meets and diverges from the default network. J Neurosci 30, 16809-16817.

Seghier, M.L., Ramlackhansingh, A., Crinion, J., Leff, A.P., Price, C.J., 2008. Lesion identification using unified segmentation-normalisation models and fuzzy clustering. Neuroimage 41, 1253-1266.

Sehm, B., Schafer, A., Kipping, J., Margulies, D., Conde, V., Taubert, M., Villringer, A., Ragert, P., 2012. Dynamic modulation of intrinsic functional connectivity by transcranial direct current stimulation. J. Neurophysiol. 108, 3253-3263.

Siegel, J.S., Snyder, A.Z., Ramsey, L., Shulman, G.L., Corbetta, M., 2016. The effects of hemodynamic lag on functional connectivity and behavior after stroke. J Cereb Blood Flow Metab 36, 2162-2176.

Simons, J.S., Spiers, H.J., 2003. Prefrontal and medial temporal lobe interactions in longterm memory. Nat Rev Neurosci 4, 637-648.

Singer, W., 1999. Neuronal synchrony: a versatile code for the definition of relations? Neuron 24 (49-65), 111-125.

Snaphaan, L., de Leeuw, F.E., 2007. Poststroke memory function in nondemented patients: a systematic review on frequency and neuroimaging correlates. Stroke 38, 198-203.

Snaphaan, L., Rijpkema, M., van Uden, I., Fernandez, G., de Leeuw, F.E., 2009. Reduced medial temporal lobe functionality in stroke patients: a functional magnetic resonance imaging study. Brain 132, 1882-1888.

Sommer, T., Rose, M., Buchel, C., 2006. Dissociable parietal systems for primacy and subsequent memory effects. Neurobiol Learn Mem 85, 243-251.

Stevens, M.C., Calhoun, V.D., Kiehl, K.A., 2005. Hemispheric differences in hemodynamics elicited by auditory oddball stimuli. Neuroimage 26, 782-792.

Strick, P.L., Dum, R.P., Fiez, J.A., 2009. Cerebellum and nonmotor function. Annu Rev Neurosci 32, 413-434.

Sun, Ya-wen, Quin, Lin-di, Zhou, Yan, Xu, Qun, Qian, Li-jun, Tao, Jing, Xu, Jian-rong, 2011. Abnormal functional connectivity in patients with vascular cognitive impairment, no dementia: A resting-state functional magnetic resonance imaging study. Behav Brain Res 223 (2), 388-394. https://doi.org/10.1016/j. bbr.2011.05.006. 
Thakral, P.P., Madore, K.P., Schacter, D.L., 2017. A Role for the Left Angular Gyrus in Episodic Simulation and Memory. J Neurosci 37, 8142-8149.

Thompson, R.F., Kim, J.J., 1996. Memory systems in the brain and localization of a memory. Proc Natl Acad Sci U S A 93, 13438-13444.

Tuladhar, A.M., Snaphaan, L., Shumskaya, E., Rijpkema, M., Fernandez, G., Norris, D.G. de Leeuw, F.E., 2013. Default Mode Network Connectivity in Stroke Patients. PLoS ONE 8, e66556.

Uncapher, M.R., Wagner, A.D., 2009. Posterior parietal cortex and episodic encoding: insights from fMRI subsequent memory effects and dual-attention theory. Neurobio Learn Mem 91, 139-154.

Vanhaudenhuyse, A., Noirhomme, Q., Tshibanda, L.J., Bruno, M.A., Boveroux, P., Schnakers, C., Soddu, A., Perlbarg, V., Ledoux, D., Brichant, J.F., Moonen, G., Maquet, P., Greicius, M.D., Laureys, S., Boly, M., 2010. Default network connectivity reflects the level of consciousness in non-communicative brain-damaged patients. Brain 133, 161-171.

Vincent, J.L., Snyder, A.Z., Fox, M.D., Shannon, B.J., Andrews, J.R., Raichle, M.E., Buckner, R.L., 2006. Coherent spontaneous activity identifies a hippocampal-parietal memory network. J. Neurophysiol. 96, 3517-3531.

Wang, L., Yu, C., Chen, H., Qin, W., He, Y., Fan, F., Zhang, Y., Wang, M., Li, K., Zang, Y., Woodward, T.S., Zhu, C., 2010. Dynamic functional reorganization of the motor execution network after stroke. Brain 133, 1224-1238.

Weissenbacher, A., Kasess, C., Gerstl, F., Lanzenberger, R., Moser, E., Windischberger, C., 2009. Correlations and anticorrelations in resting-state functional connectivity MRI: a quantitative comparison of preprocessing strategies. Neuroimage 47, 1408-1416.

Wentzel, C., Rockwood, K., MacKnight, C., Hachinski, V., Hogan, D.B., Feldman, H., Ostbye, T., Wolfson, C., Gauthier, S., Verreault, R., McDowell, I., 2001. Progression of impairment in patients with vascular cognitive impairment without dementia. Neurology 57, 714-716.

Werden, E., Cumming, T., Li, Q., Bird, L., Veldsman, M., Pardoe, H.R., Jackson, G., Donnan, G.A., Brodtmann, A., 2017. Structural MRI markers of brain aging early after ischemic stroke. Neurology 89, 116-124.

Wolf, P.A., Abbott, R.D., Kannel, W.B., 1991. Atrial fibrillation as an independent risk factor for stroke: the Framingham Study. Stroke 22, 983-988.

Xu, Y., Lin, Q., Han, Z., He, Y., Bi, Y., 2016. Intrinsic functional network architecture of human semantic processing: Modules and hubs. Neuroimage 132, 542-555.
Yan, C.G., Wang, X.D., Zuo, X.N., Zang, Y.F., 2016. DPABI: Data Processing \& Analysis for (Resting-State) Brain Imaging. Neuroinformatics 14, 339-351.

Yang, S., Jiang, C., Ye, H., Tao, J., Huang, J., Gao, Y., Lin, Z., Chen, L., 2014. Effect of integrated cognitive therapy on hippocampal functional connectivity patterns in stroke patients with cognitive dysfunction: a resting-state FMRI study. Evid Based Complement Alternat Med 2014, 962304.

Yokota, C., Minematsu, K., Hasegawa, Y., Yamaguchi, T., 2004. Long-term prognosis, by stroke subtypes, after a first-ever stroke: a hospital-based study over a 20 -year period. Cerebrovasc Dis 18, 111-116.

Yu, W., Krook-Magnuson, E., 2015. Cognitive Collaborations: Bidirectional Functional Connectivity Between the Cerebellum and the Hippocampus. Front Syst Neurosci 9, 177.

Zhang, D., Raichle, M.E., 2010. Disease and the brain's dark energy. Nat Rev Neurol 6, 15-28.

Zhang, H.Y., Wang, S.J., Liu, B., Ma, Z.L., Yang, M., Zhang, Z.J., Teng, G.J., 2010. Resting brain connectivity: changes during the progress of Alzheimer disease. Radiology 256, 598-606.

Zhang, P., Wang, J., Xu, Q., Song, Z., Dai, J., Wang, J., 2018. Altered functional connectivity in post-ischemic stroke depression: A resting-state functional magnetic resonance imaging study. Eur J Radiol 100, 156-165.

Zhao, Y., Lambon Ralph, M.A., Halai, A.D., 2018. Relating resting-state hemodynamic changes to the variable language profiles in post-stroke aphasia. Neuroimage Clin $20,611-619$.

Zheng, X., Sun, L., Yin, D., Jia, J., Zhao, Z., Jiang, Y., Wang, X., Wu, J., Gong, J., Fan, M., 2016. The plasticity of intrinsic functional connectivity patterns associated with rehabilitation intervention in chronic stroke patients. Neuroradiology 58, 417-427.

Zhou, J., Greicius, M.D., Gennatas, E.D., Growdon, M.E., Jang, J.Y., Rabinovici, G.D., Kramer, J.H., Weiner, M., Miller, B.L., Seeley, W.W., 2010. Divergent network connectivity changes in behavioural variant frontotemporal dementia and Alzheimer's disease. Brain 133, 1352-1367.

Zhou, Y., Liang, M., Tian, L., Wang, K., Hao, Y., Liu, H., Liu, Z., Jiang, T., 2007. Functional disintegration in paranoid schizophrenia using resting-state fMRI. Schizophr. Res. 97, 194-205.

Zigmond, A.S., Snaith, R.P., 1983. The hospital anxiety and depression scale. Acta Psychiatr Scand 67, 361-370. 